\title{
Impact of the mandatory Hepatitis A immunization program: before and after the vaccine in Ankara, Central of Turkey
}

\author{
Saliha Kanık Yüksek ${ }^{1}$, Hasan Tezer², Aslınur Özkaya Parlakay ${ }^{1}$, Belgin Gülhan ${ }^{1}$, \\ Ateş Kara ${ }^{3}$, Ergin Çiftçi ${ }^{4}$, Anıl Tapısız², Melda Çelik ${ }^{5}$, Halil Özdemir ${ }^{4}$, Kübra Aykaç3, \\ Tuğba Bedir Demirdağ ${ }^{2}$, Tuğçe Tural Kara ${ }^{4}$, Gamze Hayran ${ }^{1}$, Erdal İnce ${ }^{4}$ \\ ${ }^{1}$ Department of Pediatric Infectious Diseases, Ankara Hematology Oncology Children's Training and Research Hospital; \\ ${ }^{2}$ Division of Pediatric Infectious Diseases, Department of Pediatrics, Gazi University Faculty of Medicine; ${ }^{3}$ Division of \\ Pediatric Infectious Diseases, Department of Pediatrics, Hacettepe University Faculty of Medicine; ${ }^{4}$ Division of Pediatric \\ Infectious Diseases, Department of Pediatrics, Ankara University Faculty of Medicine; ${ }^{5}$ Division of Pediatric Infectious \\ Diseases, Keçiören Training and Research Hospital, Ankara, Turkey. E-mail: salihakanik@gmail.com \\ Received: 21st September 2018, Accepted: 24th October 2018
}

SUMMARY: Kanık Yüksek S, Tezer H, Özkaya Parlakay A, Gülhan B, Kara A, Çiftçi E, Tapısız A, Çelik M, Özdemir H, Aykaç K, Demirdağ TB, Tural Kara T, Hayran G, Ince E. Impact of the mandatory Hepatitis A immunization program: before and after the vaccine in Ankara, Central of Turkey. Turk J Pediatr 2019; 61: 677-685.

In Turkey Hepatitis A virus (HAV) infection is considered to be moderateendemic. Hepatitis A vaccine was included in the mandatory vaccination schedule of Turkey on November 2012. We aimed to evaluate the cases of HAV infection followed in Ankara, which is located in the center of Central Anatolia, retrospectively according to the date of the administration of the mandatory hepatitis A vaccine. A total of 272 children followed-up between January 2008 and December 2015 for HAV infection in five separate hospitals were enrolled to the study. There were $200(68.2 \%)$ cases in the pre-vaccination group, 72 $(31.74 \%)$ cases in the post-vaccination group, and $55.1 \%$ were male in total. The immunization status were as follow; $89.7 \%(\mathrm{n}=244)$ unvaccinated, $0.4 \%$ $(n=1)$ vaccinated and $9.9 \%(n=27)$ with unknown immune status. There was a statistically significant difference between the groups in hospitalization rates, but no statistically significant differences in hospitalization indications, length of hospital stay, complication types and proportions, and normalization period of transaminases. The national hepatitis A immunization program in Turkey has had a significant impact when the targeted population is considered, with suggestive herd protection effects.

Key words: Hepatitis A vaccine, immunization program, impact, children.

Hepatitis A infection is an acute infectious liver disease caused by Hepatitis A virus (HAV), which is a member of the Picornaviridae family, and is an important issue affecting public health globally. ${ }^{1,2}$ In Turkey, HAV infection is considered as moderate-endemic based on the prevalence data between $8 \%$ and $88 \%$ varying according to regions and cities. Determining the exact incidence of the disease is difficult because of the incomplete notification of the disease, and the fact that $90 \%$ of young children remain asymptomatic. ${ }^{2-4}$ Endemicity varies by geographic region, socioeconomic status and sanitation conditions such as ability to reach safe drinking water. ${ }^{4,5}$ The infection is transmitted mainly by the fecal-oral route through contact with infected cases, unhealthy drinking water and food. ${ }^{6}$ Following the incubation period of 2-6 weeks, HAV infection can manifest in cholestatic, non-cholestatic, subfulminant or fulminant forms. ${ }^{1,4}$

Endemicity of HAV infection and the prevalence of anti-HAV antibodies are highly related with the economic status and sanitary conditions of the regions or countries. ${ }^{1,7}$ The most effective 
approach for hepatitis $\mathrm{A}$ is protection against the disease. ${ }^{4,7}$ Improved sanitation, which is a major method of prevention decreases hepatitis A-releated morbidity and mortality rates, but its concequence is that it may increase the risk of getting infected later in life. ${ }^{8,9}$ In this sense, vaccination against $\mathrm{HAV}$ is an effective measure to provide immunization and reduce its incidence all through human life. ${ }^{10,11}$ Active immunization is very important for the following reasons; (I) increasing number of susceptible people in relation to the developmental ratios of the countries, (II) shifts of the infection age to older ages, (III) increased travel rates to the regions where the disease is endemic, and (IV) persistance of fulminant disease risk even if it is low. ${ }^{7,10,12}$ Several HAV vaccines have been available including both inactivated and live attenuated vaccine, since the 1990s. ${ }^{4}$ Studies have shown the vaccine to induced high levels of immunogenicity, and detectable antibodies againts HAV have persisted for about 20 years in more than $97 \%$ of individuals. ${ }^{4,13}$ In 1996, the Advisory Committee on Immunization Practices (ACIP) of the American Academy of Pediatrics recommended routine immunization to only selected groups. But ACIP expanded its recommendations in 1999, and the recommendations changed to the immunization of all children at one year of age in the United States in 2006. ${ }^{14}$ Finally, the World Health Organization recommends that HAV vaccination should be included into the national immunization schedules for children aged $\geq 1$ year on the basis of acute HAV incidence, shift in endemicity (from high to intermediate), and also consideration of cost effectiveness. ${ }^{4}$ Following this strong recommendation, HAV vaccination programmes have been introduced and have reduced the incidence of $\mathrm{HAV}$ infection in many countries. ${ }^{15-18}$

The hepatitis A vaccine was introduced to the mandatory national immunization program of Turkey in November 2012 (the first dose at the end of the 18th month and second dose at the end of the 24th month). ${ }^{2}$ In this study, cases with HAV infection at five different hospitals in Ankara, located in the center of Central Anatolia, were evaluate according to the date of the administration of the mandatory hepatitis A vaccine. Primarily, hospital admissions and hospitalization rates, indications for hospitalization, length of hospital stay, complications and recovery time due to hepatitis A infection were compared before and after the vaccination periods.

\section{Material and Methods}

A total of 272 children (0 to 18 years of age) followed-up between January 2008 and December 2015 for HAV infection in five hospitals in Ankara were enrolled in the study. Ankara is the capital city and at the center of Turkey, also the second most populated city with more than five million inhabitants. Centers with the number of patients in the study are listed as follows: (Center 1) Ankara Hematology Oncology Children's Training and Research Hospital 186 patients; (Center 2) Hacettepe University Faculty of Medicine Hospital 35 patients; (Center 3) Ankara University Faculty of Medicine Hospital 26 patients; (Center 4) Gazi University Medical Faculty Hospital 22 patients; and (Center 5) Keçiören Training and Research Hospital 3 patients. Three cases from Center 5 were included with the cases of Center 1, due to the regional proximity of the hospitals. The cases that were admitted before November 2012, the date on which the HAV vaccine was started to be administered in the routine vaccination schedule, were grouped as pre-vaccination group and the applicants who applied after this date were grouped as the post-vaccination group. The descriptive characteristics of the patients such as age and gender, the date they were diagnosed with HAV, the HAV vaccination status, the contact history with HAV, risk factors such as crowded home and underlying disease, and province were recorded. Diagnosis of all the patients was made by the detection of serum immunoglobulin M (IgM) anti-HAV antibodies at all of the centers. Complaints on admission, total symptom duration prior to admission, and physical examination findings were examined. Laboratory studies on admission (Hemogram, liver function tests, total and direct bilirubin levels with other biochemical tests, $\mathrm{C}$ reactive protein, erythrocyte sedimentation rate, prothrombin time [PT] and activated thromboplastin time [aPTT]), and abdominal ultrasonography 
findings (if applied) of the pateints were recorded. Hospitalization indications (if present) and length of hospital stay (if present), complications, intensive care need, and normalization period of transaminases were investigated. Complications was categorised as cholestatic hepatitis, recurrent hepatitis, fulminant hepatitis, death, and the others (such as postviral encephalitis, Guillain-Barré syndrome, cholecystitis, acute pancreatitis, aplastic anemia, agranulocytosis, thrombocytopenic purpura, vasculitis, and cryoglobulinemia). Cholestatic hepatitis was defined as total bilirubin level higher than 10 $\mathrm{mg} / \mathrm{dl}$ and direct bilirubin level higher than $50 \%$ of the total bilirubin level. ${ }^{19}$ Recurrent hepatitis was defined as recurrence of the liver function test abnormalities during the six months following partial or total recovery of infection with ongoing anti-HAV IgM seropositivity. ${ }^{20,21}$ Fulminant hepatitis was defined as the severe impairment in hepatic functions and hepatic encephalopathy presence in the absence of preexisting liver disease. ${ }^{22}$

Research ethics board approval was obtained for the study from Ankara Hematology
Oncology Children's Training and Researh Hospital Ethics Committee (Approval number: 01.2016/037), and all investigational procedures conform to the Declaration of Helsinki guiding principles.

Statistical analysis was performed with the Statistical Package for the Social Sciences version 17.0 (SPSS Inc., Chicago, IL, USA, 2009). Continuous variables were specified as arithmetical means with standard deviations (SD). While numerical data were compared between the two groups, t-test was applied to the normal distributions in independent groups, and Mann Whitney U test was applied to those who did not normally disperse. Qualitative variables were compared with chisquare or Fisher's exact test. A p value of < 0.05 was considered statistically significant.

\section{Results}

Of the 272 cases included in the study, $55.1 \%$ were male. There were $200(68.2 \%)$ cases in the pre-vaccination group, and $72(31.74 \%)$ cases in the post-vaccination group. According

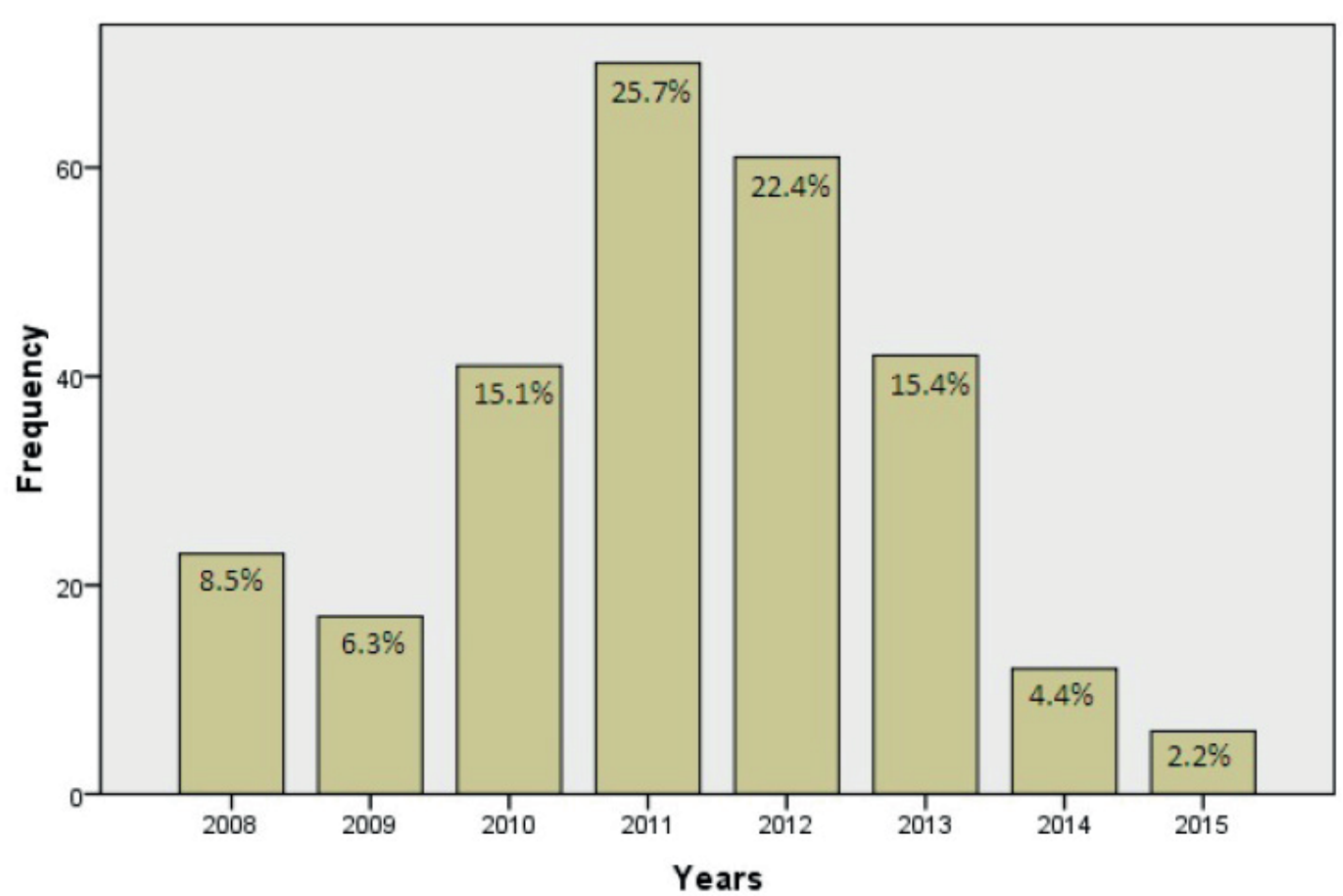

Fig. 1. Distribution of case numbers (vertical values) by years (horizontal values) Ratios of cases according to general aggregation is stated as percentage. 
to the centers the distribution of the patients was as follows: Center $1 \% 68.4$, Center 2 $\% 12.9$, Center $3 \% 9.6$, Center $4 \% 8.1$, and Center $5 \% 1.1$. The mean age of the patients was $9.5 \pm 3.72$ years in the pre-vaccination group and $8.79 \pm 4.01$ years in the postvaccination group, and the general mean age was $9.32 \pm 3.8(1-18)$ years $(p=0,179)$. The immunization status with the HAV vaccine were as follows: $89.7 \%(\mathrm{n}=244)$, unvaccinated cases, $0.4 \%(n=1)$ vaccinated cases and $9.9 \%(\mathrm{n}=27)$ with unknown immune status. Distribution of cases by years is given in Figure 1. Contact history with an individual known to be infected with HAV in the pre-vaccination group was present in $13 \%$, not present in $45.5 \%$ and unknown in $41.5 \%$, and in the post-vaccination group present in $16.7 \%$, not present in $22 \%$ and unknown in $52.8 \%$. The risk factor for HAV infection was $19 \%$ in the pre-vaccination group and $13 \%$ in the post-vaccination group. Mean symptom duration prior to admission was $6.32 \pm 7.68$ (1-90) days in the pre-vaccination group, and $4.81 \pm 4.11$ (1-30) days in the post-vaccination group. There was a statistically significant difference between the two groups for the symptom duration prior to admission ( $\mathrm{p}=$ 0.014). Distribution of symptoms according to the groups is summarized in Table I. In addition, the comparison of laboratory tests according to the groups is also shown in Table II. Abdominal utrasonography was studied in $44.9 \%$ of the patients $(48.5 \%$ in the prevaccinated group [ $\mathrm{n}=97]$, and $34.7 \%$ in the postvaccinated group $[\mathrm{n}=25])(\mathrm{p}=0.044)$. The findings detected by ultrasonography according to the groups are summarized in Table III.

Hospitalization rates were $54.5 \%(\mathrm{n}=109)$ in the pre-vaccination group, $30.6 \%(\mathrm{n}=$ 22 ) in the post-vaccination group, and $48.2 \%$ $(\mathrm{n}=131)$ in total. Statistically significant difference was found between the groups ( $p$ $=0.001)$ for hospitalization rates. When indications for hospitalization were examined, the order of frequency was as follows in prevaccination group: feeding difficulty $36 \%$, vomiting $3.5 \%$, dehydration $1 \%$, changing in consciousness $1 \%$, for follow-up purposes $4 \%$, coagulopathy $4 \%$, cytopenia $1 \%$, abdominal pain $3.5 \%$, bleeding $0.5 \%$. In the other group the indications were as follows: feeding difficulty $20.8 \%$, vomiting $1.4 \%$, changing in consciousness $1.4 \%$, for follow-up purposes $1.4 \%$, coagulopathy $2.8 \%$, abdominal pain $1.4 \%$, bleeding $1.4 \%$. There were no statistically significant differences between the two groups in hospitalization indications. In the comparison for the length of hospital stay, it was $4.83 \pm 2.72$ (1-20) days in the prevaccination group and $5.73 \pm 8.99$ (1-45) days in the post-vaccination group, this was not statistically significant $(\mathrm{p}=0.182)$. Need for intensive care was not detected in any of the patients in the pre-vaccination group, and only one patient $(1.4 \%)$ required intensive care due to fulminant course and liver transplantation in the post-vaccination group. Complications in patients were as follows; cholestatic hepatitis $7.4 \%(n=20)$, fulminant hepatitis $1.5 \%(\mathrm{n}=4)$, recurrent hepatitis $0.7 \%(\mathrm{n}=$ 2 ), and the other (thrombocytopenic purpura) $0.4 \%(n=1)$. Distribution of complications according to groups was: cholestatic hepatitis $8 \%(n=16)$, fulminant hepatitis $1.5 \%(n=3)$, recurrent hepatitis $1 \%(n=2)$, and the other (thrombocytopenic purpura) $0.5 \%(\mathrm{n}=1)$ in the pre-vaccination group, and cholestatic hepatitis $4.4 \%(n=4)$, fulminant hepatitis $1.3 \%(\mathrm{n}=1)$ in post-vaccination group. No deaths due to HAV infection were observed in any of the patients. There was no statistically significant difference in complication types and proportions between the groups ( $\mathrm{p}=$ $0.934)$. Normalization period of transaminases was $29.77 \pm 21.97$ (3-120) days in the prevaccination group and $33.79 \pm 25.86(8-125)$ days in the post-vaccination group, with no statistically significant difference between the two groups $(p=0.552)$.

\section{Discussion}

All inactivated hepatitis A vaccines, which are approved for use in children and do not have a predominance in terms of efficacy and side effects, are also available in our country. ${ }^{14,23}$ In Turkey, Hepatitis A seroprevelance studies have been performed in some groups and regions before, but we believe this study is important as it is the first observational-descriptive study comparing the pre- and post-vaccination period. ${ }^{2,3,24}$ Seroprevalence studies are of vital importance, because HAV notifications may 
Table I. Distribution of Symptoms and Physical Examinations of the Patients on Admission According to the Groups and $p$ Values.

\begin{tabular}{|c|c|c|c|c|}
\hline Symptom & $\begin{array}{c}\text { Pre-vaccination group } \\
(\%)\end{array}$ & $\begin{array}{c}\text { Post-vaccination group } \\
(\%)\end{array}$ & Total & $p$ value* \\
\hline Nausea & 58.1 & 31 & 49.1 & 0.051 \\
\hline Vomiting & 70.2 & 54.9 & 66.2 & $0.02^{* *}$ \\
\hline Abdominal pain & 60.1 & 53.5 & 58.4 & 0.33 \\
\hline Jaundice & 52 & 74.6 & 58 & $0.001^{* *}$ \\
\hline Dark colored urine & 22.7 & 12.7 & 19.7 & 0.83 \\
\hline Light colored gaita & 2.5 & 5.6 & 3.3 & 0.189 \\
\hline Weakness & 29.8 & 29.6 & 29.7 & 0.972 \\
\hline Itching & 3 & 7 & 4.1 & 0.134 \\
\hline Fever & 31.8 & 22.5 & 29.7 & 0.141 \\
\hline Arthralgia & 0.5 & 0 & 0.4 & 0.736 \\
\hline Bleeding & 1.5 & 2.8 & 1.9 & 0.397 \\
\hline Diarrhea & 9.1 & 8.5 & 8.9 & 0.871 \\
\hline Anorexia & 9.6 & 9.9 & 9.7 & 0.949 \\
\hline Dizziness & 1.5 & 0 & 1.1 & 0.397 \\
\hline Headache & 2.5 & 0 & 1.9 & 0.213 \\
\hline Syncope & 0.5 & 0 & 0.4 & 0.736 \\
\hline Rash & 1 & 0 & 0.7 & 0.541 \\
\hline Cough & 2 & 1.4 & 1.9 & 0.603 \\
\hline \multicolumn{5}{|l|}{ Physical examination } \\
\hline Fever & 9.6 & 1.4 & 7.4 & $0.024^{* *}$ \\
\hline Jaundice & 71.7 & 84.5 & 75.1 & $0.033^{* *}$ \\
\hline Abdominal sensitivity & 23.2 & 19.7 & 22.3 & 0.542 \\
\hline Dehydration & 6.1 & 4.2 & 5.6 & 0.407 \\
\hline Consciousness Changing & 1 & 0 & 0.7 & 0.541 \\
\hline Hepatomegaly & 33.3 & 29.6 & 32.3 & 0.562 \\
\hline Splenomegaly & 3 & 0 & 2.2 & 0.156 \\
\hline Rash & 1.5 & 1.4 & 1.5 & 0.714 \\
\hline
\end{tabular}

*Pearson chi-square and Fisher's exact test were applied

${ }^{* *}$ was considered significant because of $p<0.05$

underestimate the true incidence especially in young children due to asymptomatic illness. Observational-descriptive studies like ours are valuable for identifying the pattern of disease in relation to vaccine in clinical practice.

As a result of the study, significant decline in hospital application for HAV infection was documented between the pre- and post-vaccine periods $(68.2 \%$ and $31.74 \%$, respectively). This result may be related to substantial herd protection, because HAV vaccination rate in the study patients was negligible. As known, young children play an important role in the transmission of infection to other children and adults, because they are usually asymptomatic and have lower personal hygiene levels. ${ }^{5}$ So, an effective vaccination program in this group will also prevent transmission, thus providing effective protection in other age groups including un-immunized individuals. ${ }^{6,7}$ 
Table II. Results and Comparisons of Laboratory Tests According to the Groups.

\begin{tabular}{|c|c|c|c|c|}
\hline & $\begin{array}{c}\text { Pre-vaccination group } \\
\text { Mean } \pm \mathrm{SD} \\
(\min -\max )\end{array}$ & $\begin{array}{l}\text { Post-vaccination group } \\
\text { Mean } \pm \mathrm{SD} \\
(\text { min-max })\end{array}$ & $\begin{array}{c}\text { Total } \\
\text { Mean } \pm \text { SD } \\
(\min -\max )\end{array}$ & $p$ value* \\
\hline \multicolumn{5}{|l|}{ Hemogram } \\
\hline$W B C\left(x 10^{3} / \mu L\right)$ & $\begin{array}{c}6.64 \pm 2.74 \\
(2.7-25.9)\end{array}$ & $\begin{array}{c}7.31 \pm 2.56 \\
(1.8-15.2)\end{array}$ & $\begin{array}{c}7.04 \pm 2.69 \\
(1.8-25.9)\end{array}$ & 0.115 \\
\hline$H g(g / d L)$ & $\begin{array}{c}13.46 \pm 1.35 \\
(9-17)\end{array}$ & $\begin{array}{c}13.13 \pm 1.47 \\
(8-15)\end{array}$ & $\begin{array}{c}13.38 \pm 1.39 \\
(8-17)\end{array}$ & 0.088 \\
\hline Plt $\left(x 10^{3} / \mu L\right)$ & $\begin{array}{c}272.170 \pm 95.953 \\
(2-559)\end{array}$ & $\begin{array}{c}277.57 \pm 94.14 \\
(102-543)\end{array}$ & $\begin{array}{c}273.624 \pm 95.318 \\
(2-559)\end{array}$ & 0.583 \\
\hline $\mathrm{CRP}(\mathrm{mg} / \mathrm{dL})$ & $\begin{array}{l}1.36 \pm 3.61 \\
(0.03-39.1)\end{array}$ & $\begin{array}{c}0.68 \pm 0.76 \\
(0.03-5)\end{array}$ & $\begin{array}{l}1.18 \pm 3.12 \\
(0.03-39.1)\end{array}$ & 0.716 \\
\hline ESR $(\mathrm{mm} / \mathrm{hr})$ & $\begin{array}{c}29.93 \pm 18.18 \\
(5-98)\end{array}$ & $\begin{array}{c}22.88 \pm 19.09 \\
(4-70)\end{array}$ & $\begin{array}{c}28.64 \pm 18.45 \\
(4-98)\end{array}$ & 0.085 \\
\hline \multicolumn{5}{|l|}{ Blood biochemistry } \\
\hline$A S T(U / L)$ & $\begin{array}{c}1232.70 \pm 1020.24 \\
(40-7787)\end{array}$ & $\begin{array}{c}965.69 \pm 890.54 \\
(68-4404)\end{array}$ & $\begin{array}{c}1161.76 \pm 974.48 \\
(40-7787)\end{array}$ & $0.028^{* *}$ \\
\hline$A L T(U / L)$ & $\begin{array}{c}1429.91 \pm 810.12 \\
(48-4599)\end{array}$ & $\begin{array}{c}1236.81 \pm 784.88 \\
(81-3844)\end{array}$ & $\begin{array}{c}1378.8 \pm 806.61 \\
(48-4599)\end{array}$ & 0.054 \\
\hline $\begin{array}{l}\text { Total bilirubin } \\
(m g / d L)\end{array}$ & $\begin{array}{l}5.42 \pm 3.96 \\
(0.16-34.96)\end{array}$ & $\begin{array}{c}5.54 \pm 2.96 \\
(0.55-17.6)\end{array}$ & $\begin{array}{l}5.46 \pm 3.72 \\
(0.16-34.96)\end{array}$ & 0.297 \\
\hline $\begin{array}{l}\text { Direct bilirubin } \\
(m g / d L)\end{array}$ & $\begin{array}{l}4.28 \pm 3.25 \\
(0.02-29.07)\end{array}$ & $\begin{array}{l}4.14 \pm 2.16 \\
(0.16-11.6)\end{array}$ & $\begin{array}{c}4.24 \pm 3 \\
(0.02-29.07)\end{array}$ & 0.749 \\
\hline$G G T(U / L)$ & $\begin{array}{c}171.33 \pm 103.87 \\
(3.8-518)\end{array}$ & $\begin{array}{c}137.58 \pm 72.99 \\
(29-347)\end{array}$ & $\begin{array}{c}164.37 \pm 99.1 \\
(3.8-518)\end{array}$ & 0.075 \\
\hline$A L P(U / L)$ & $\begin{array}{c}613.24 \pm 462.64 \\
(31-3063)\end{array}$ & $\begin{array}{c}415.84 \pm 197.28 \\
(181-1047)\end{array}$ & $\begin{array}{c}561.5 \pm 418.77 \\
(31-3063)\end{array}$ & $0.001^{* *}$ \\
\hline Glucose $(m g / d L)$ & $\begin{array}{l}94.9 \pm 21.56 \\
\quad(54-186)\end{array}$ & $\begin{array}{l}92.22 \pm 16.98 \\
\quad(51-153)\end{array}$ & $\begin{array}{l}94.18 \pm 20.42 \\
\quad(51-186)\end{array}$ & 0.072 \\
\hline Albumin $(g r / d L)$ & $\begin{array}{c}3.9 \pm 0.62 \\
(3-4.6)\end{array}$ & $\begin{array}{c}3.94 \pm 0.53 \\
(2-4.1)\end{array}$ & $\begin{array}{c}3.91 \pm 1.41 \\
(2-4.1)\end{array}$ & 0.611 \\
\hline$B U N(m g / d L)$ & $\begin{array}{c}16.86 \pm 8.1 \\
(2.8-41)\end{array}$ & $\begin{array}{c}17.18 \pm 8.3 \\
(0.3-35)\end{array}$ & $\begin{array}{c}16.95 \pm 8.14 \\
(0.3-41)\end{array}$ & 0.786 \\
\hline Creatinine $(m g / d L)$ & $\begin{array}{l}0.47 \pm 0.16 \\
(0.1-1)\end{array}$ & $\begin{array}{l}0.48 \pm 0.46 \\
(0.1-4.1)\end{array}$ & $\begin{array}{l}0.48 \pm 0.28 \\
(0.1-4.1)\end{array}$ & 0.106 \\
\hline $\mathrm{Na}(m E q / L)$ & $\begin{array}{c}137.53 \pm 3.43 \\
(126-145)\end{array}$ & $\begin{array}{c}137.38 \pm 3.2 \\
(132-145)\end{array}$ & $\begin{array}{c}137.49 \pm 3.36 \\
(126-145)\end{array}$ & 0.752 \\
\hline$K(m E q / L)$ & $\begin{array}{l}4.19 \pm 0.54 \\
(2.3-4.9)\end{array}$ & $\begin{array}{l}4.29 \pm 0.72 \\
(3.1-5.9)\end{array}$ & $\begin{array}{l}4.23 \pm 0.59 \\
(2.3-5.9)\end{array}$ & 0.255 \\
\hline$L D H(U / L)$ & $\begin{array}{c}817.84 \pm 790.27 \\
(174-8836)\end{array}$ & $\begin{array}{c}669.96 \pm 585.5 \\
(220-1845)\end{array}$ & $\begin{array}{c}771.3 \pm 689.39 \\
(174-8836)\end{array}$ & $0.032^{* *}$ \\
\hline \multicolumn{5}{|l|}{ Coagulation tests } \\
\hline$p T$ & $\begin{array}{l}16.62 \pm 3.59 \\
\quad(10-30)\end{array}$ & $\begin{array}{l}16.01 \pm 3.66 \\
(10-33)\end{array}$ & $\begin{array}{l}16.44 \pm 3.62 \\
\quad(10-33)\end{array}$ & 0.245 \\
\hline aPTT & $\begin{array}{l}34.77 \pm 6.43 \\
\quad(8-238)\end{array}$ & $\begin{array}{l}33.32 \pm 4.62 \\
(23-44)\end{array}$ & $\begin{array}{l}34.01 \pm 4.02 \\
\quad(8-238)\end{array}$ & 0.051 \\
\hline$I N R$ & $\begin{array}{c}1.19 \pm 0.25 \\
(1-2)\end{array}$ & $\begin{array}{c}1.20 \pm 0.48 \\
(1-5)\end{array}$ & $\begin{array}{c}1.20 \pm 0.33 \\
(1-5)\end{array}$ & 0.817 \\
\hline
\end{tabular}

WBC: White blood cell count, Hg: Hemoglobin, Plt: Platelets, CRP: C-reactive protein,

ESR: Erythrocyte sedimentation rate, AST: Aspartate aminotransferase, ALT: Alanin aminotransferase, GGT: Gamma glutamyl transferase, ALP: Alkaline phosphatase, BUN: Blood urea nitrogen, Na: Sodium, K: Potassium, LDH: Lactate dehydrogenase, pT: Prothrombin time, aPTT: Activated thromboplastin time, INR: International normalised ratio

${ }^{*}$ Mann Whitney $U$ test and $t$-test were applied

** was considered significant because of $p<0.05$ 
Table III. The Findings of the Patients Detected by Ultrasonography According to the Groups.

\begin{tabular}{lcccc}
\hline $\begin{array}{l}\text { Abdominal } \\
\text { ultrasonography finding }\end{array}$ & $\begin{array}{c}\text { Pre-vaccination group } \\
(\%)\end{array}$ & $\begin{array}{c}\text { Post-vaccination group } \\
(\%)\end{array}$ & Total & $p$ value* \\
\hline Hepatomegaly & 67 & 76 & 68.9 & 0.387 \\
Splenomegaly & 34 & 40 & 35.2 & 0.577 \\
Lymphadenopathy & 53.6 & 60 & 54.9 & 0.567 \\
Intraabdominal fluid & 19.6 & 40 & 23.8 & $0.033^{* *}$ \\
Gall bladder edema / wall & 46.4 & 56 & 48.4 & 0.391 \\
thickening & & & & \\
Normal & 7.2 & 8 & 7.3 & 0.572 \\
\hline
\end{tabular}

*Pearson chi-square test was applied

**was considered significant because of $p<0.05$

Substantial herd protection effects of universal childhood immunization programs for HAV vaccines have been documented in many countries such as Israel, Argentina and USA. ${ }^{15-}$ 18 The national hepatitis A immunization program of Turkey appears to have been highly effective to reducing the incidence of HAV infection, not only in the province of Ankara but all over the country year by year. According to the Ministry of Health data, since the routine administration of the Hepatitis A vaccine at the end of 2012, the incidence of the illness which was 4.79 per 100,000 in 2012 has fallen to 0.9 per 100,000 in 2015 , and diseaserelated mortality was not detected after the initiation of the immunization program when the mortality rate was 0.03 per one million before. ${ }^{25}$ Pre-vaccination studies from Turkey showed that anti-HAV seroprevalence has shifted to further ages. ${ }^{24}$ However, there is no seroprevalence study conducted in large series after the vaccination period.

Contact history of the patients with a HAV infected individual was largely absent or unknown both in pre-vaccination and postvaccination groups, which overlaps with the fact that the illness is asymptomatic substantially in the childhood age group, when children are estimated to have more contact with each other. ${ }^{1,4,7}$ The median age of cases was similar in the pre- and post-vaccination groups. Although hepatitis A vaccination is associated with a decrease in the incidence of childhood illness and causes shift to older ages in disease, this result indicates that the affected age group does not change much in the symptomatic group. ${ }^{17,18,24}$ When the distribution of symptoms between groups is considered, there was no significant difference between the groups except for vomiting and jaundice. Similarly, there was no statistical difference between the groups except for fever and jaundice on physical examination. Although the results concerning symptom distribution and physical examination findings may not be intepreted as being meaningful in practice it should be noted that the expectation for reduction in symptomatic HAV infections has also been expressed in previous studies. ${ }^{10,26}$ There was no significant difference between the groups except for AST, ALP and LDH in laboratory parameters. We do not interpret this result as being meaningful in practice even though the admission period was shorter in the post-vaccination group. According to the results of our study in general, it can be said that the disease does not cause any serious difference in the symptomatic group in terms of clinical, laboratory and radiological findings after the vaccination period compared to prevaccination period.

Management of HAV infection includes supportive care and treatment of serious complications. ${ }^{1,20}$ Hospitalization might be necessary for dehydratation as a result of vomiting, and signs or symptoms of acute liver failure as in other acute viral hepatitis., ${ }^{1,15}$ In particular, fulminant hepatitis A requires intensive care and liver transplantation. ${ }^{20,22}$ Significant decline was documented in hospitalization rate in the post-vaccination group while there was no difference between the groups in hospitalization indications. This result may be explained by an increase 
in the social awareness of the families about the disease. Because when the parents of the children care about the symptoms of the disease, the period between the onset of symptoms and the time of admission to the hospital will be affected. Parallel to this conclusion, in result of our study the mean symptom duration prior to admission was detected significantly shorter in post-vaccination group. Unlike our study, Thompson and colleagues ${ }^{27}$ reported that there was no difference in hospitalizations between the pre- and post-vaccination periods in their Australian national hepatitis A immunization program study. According to our study, although we have found a lower hospitalization rate in post-vaccination group, it can be said that it has no effect on the length of hospital stay. In addition, necessity of liver transplantation and intensive care due to fulminant hepatitis A in only one patient among all patients is compatible with literature data.

Although HAV infection is mainly a selflimited disease, some cases may develop severe complications or even mortality. The severity of illness is directly related to age. ${ }^{1,4}$ As the age increases with comorbid disease, both complications and death increase in serious proportion after the childhood period. ${ }^{4,20}$ As a result of the study, no significant difference between the groups for neither the rates nor the types of complications was idendified, this could be because the disease-related complications are not actually observed in children. It should be noted that universal Hepatitis A vaccination of children has been associated with a greater risk of more severe disease with the shift of the infection to an older age in various studies. ${ }^{4,26,27}$ To fully interpret the impact of the mandatory Hepatitis A immunization program for children, there is a need for HAV infection studies in older age groups in Turkey. In the majority of patients with HAV infection, full clinical and biochemical recovery is observed within three months, and complete recovery is observed by six months in nearly all patients without any chronicity. ${ }^{19,21}$ According to our study, the normalization period of transaminases and duration of full recovery were not affected in post-vaccination period, in symptomatic patients.
Some limitations of this study should be mentioned. First, this study analysed only the data of the patients who were symptomatic enough to be referred to the hospital. Most probably, patients with asymptomatic or mild clinical presentation were missed. So, this study does not reflect the true incidence of the disease. However, it still provides valuable epidemiological information about HAV-infected children with clinical severity. Another limitation is that the cost-utility of HAV vaccination has not been examined. But it may be said that similar results will be valid for our country as the cost-effectiveness and cost-utility of the HAV vaccination program has already been proven in a number of studies from several countries..$^{28-31}$ Despite the fact that the province in which the study is conducted is at the center of the country, there is a need for descriptive studies to be carried out throughout the country, as the incidence of the disease varies considerably by regions and cities of Turkey.

In conclusion, according to the results of this study, the national hepatitis A immunization program in Turkey has had a significant impact when the targeted population is considered, with suggestive herd protection effects. But, to identify and interpret all the effects of the universal hepatitis A immunization program globally will need extensive evaluation. Strict seroprevelance and surveillance programs and detailed studies are necessary in this regard.

\section{REFERENCES}

1. Matheny SC, Kingery JE. Hepatitis A. Am Fam Physician 2012; 86: 1027-1034.

2. Karaman S, Karaman K, Kizılyıldız BS, et al Seroprevalence of hepatitis a and associated factors among 1-15 year old children in Eastern Turkey. Int J Clin Exp Med 2015; 8: 19394-19399.

3. Kara HI. Akut Viral Hepatit A. Türk Aile Hek Derg 2007; 11: 177-184.

4. WHO position paper on hepatitis A vaccines - June 2012. Wkly Epidemiol Rec 2012; 87: 261-276.

5. Ximenes RA, Martelli CM, Amaku M, et al; Hepatitis Study Group. Modelling the force of infection for hepatitis A in an urban population-based survey: a comparison of transmission patterns in Brazilian macro-regions. PLoS One 2014; 9: e94622. 
6. Lima LR, De Almeida AJ, Tourinho Rdos S, Hasselmann B, Ximenez LL, De Paula VS. Evidence of hepatitis A virus person-to-person transmission in household outbreaks. PLoS One 2014; 9: e102925.

7. Havelaar AH, Kirk MD, Torgerson PR, et al; World Health Organization Foodborne Disease Burden Epidemiology Reference Group. World Health Organization Global Estimates and Regional Comparisons of the Burden of Foodborne Disease in 2010. PLoS Med 2015; 12: e1001923.

8. Lozano R, Naghavi M, Foreman K, et al. Globaland regional mortality from 235 causes of death for 20 age groups in 1990 and 2010: a systematic analysis for the Global Burden of Disease Study 2010. Lancet 2012; 380: 2095-2128.

9. Vitral CL, Ospina FL, Artimos S, et al. Decliningprevalence of hepatitis A virus antibodies among children from low socio-economic groups reinforces the need for the implementation of hepatitis A vaccination in Brazil. Mem Inst Oswaldo Cruz 2012; 107: 652-658.

10. Carlos F, Gómez JA, Anaya P, Romano-Mazzotti L. Health economic assessment of universal immunization of toddlers against Hepatitis AVirus (HAV) in Mexico. Hum Vaccin Immunother 2016; 12: $52-63$.

11. Zhuang FC, Qian W, Mao ZA, et al. Persistent efficacy of live attenuated hepatitis A vaccine (H2-strain)after a mass vaccination program. Chin Med J (Engl) 2005; 118: 1851-1856.

12. Martínez A, Broner S, Sala MR, et al; and the Working Group for the Study Hepatitis a in Catalonia. Changes in the epidemiology of hepatitis A outbreaks 13 years after the introduction of a mass vaccination program. Hum Vaccin Immunother 2015; 11: 192-197.

13. Van Herck K, Van Damme P. Inactivated hepatitis A vaccine-induced antibodies: follow-up and estimates of long-term persistence. J Med Virol 2001; 63: 1-7.

14. Ogholikhan S, Schwarz KB. Hepatitis vaccines. Vaccines (Basel) 2016; 4: doi: 10.3390.

15. Daniels D, Grytdal S, Wasley A. Surveillance for acute viral hepatitis - United States, 2007. MMWR Surveill Summ 2009; 58: 1-27.

16. Dagan R, Leventhal A, Anis E, Slater P, Ashur Y, Shouval D. Incidence of hepatitis A in Israel following universal immunization of toddlers. JAMA 2005; 294: 202-210.

17. Chodick G, Heymann AD, Ashkenazi S, Kokia E, Shalev V. Long-term trends in hepatitis A incidence following the inclusion of Hepatitis A vaccine in the routine nationwide immunization program. J Viral Hepat 2008; 15: 62-65.

18. Vacchino MN. Incidence of hepatitis A in Argentina after vaccination. J Viral Hepat 2008; 15: 47-50.
19. Molina Merino A, Martínez-Huguet F, Asensi Monzó MT, Brines Solanes J, Codoñer Franch P. Cholestatictype hepatitis in childhood. An Esp Pediatr 1998; 49: 253-256.

20. Jelić O, Fornet-Sapcevski J, Kovacevíc L, Pandak N, Jelić D. Recurrences of viral hepatitis A. Acta Med Iugosl 1990; 44: 565-576.

21. Polson J, Lee WM; American Association for the Study of Liver Disease. American Association for the Study of Liver D: AASLD Position Paper: The Management of Acute Liver Failure. Hepatology 2005; 41: 11791197.

22. Yoldaş Ö, Bulut A, Altındiş M. Hepatit A enfeksiyonlarına güncel yaklaşım. Viral Hepatit Dergisi 2012; 18: 81-86.

23. Alhan E, Kozanoğlu B, Tümgör G, Çelik Ü, Yaman A, Bozdemir N. Epidemiological shift of hepatitis A in central Adana, Turkey. Turk J Gastroenterol 2014; 25: 6-8.

24. Ministry of Health of the Republic of Turkey, Public Health Institution of Turkey. Statistical Data of Department of Preventable Diseases with Vaccine, 30 March 2016, Available at: https://www.thsk. gov.tr/component/k2/353-istatiksel-veriler/asi-ileonlenebilir-hastaliklar-daire-baskanligi-istatikselverileri.html. (last accessed 15 September 2018)

25. Van Effelterre T, De Antonio-Suarez R, Cassidy A, Romano-Mazzotti L, Marano C. Model-based projections of the population-level impact of hepatitis A vaccination in Mexico. Hum Vaccin Immunother 2012; 8: 1099-1108.

26. Thompson C, Dey A, Fearnley E, Polkinghorne B, Beard F. Impact of the national targeted Hepatitis A immunisation program in Australia: 2000-2014. Vaccine 2017; 35: 170-176.

27. Mellou K, Sideroglou T, Papaevangelou V, et al. Considerations on the current universal vaccination policy against hepatitis A in Greece after recent outbreaks. PLoS One 2015; 10: e0116939.

28. Martinelli D, Bitetto I, Tafuri S, Lopalco PL, Mininni RM, Prato R. Control of hepatitis A by universal vaccination of children and adolescents: an achieved goal or a deferred appointment? Vaccine 2010; 28: 6783-6788.

29. Jacobs RJ, Greenberg DP, Koff RS, Saab S, Meyerhoff AS. Regional variation in the cost effectiveness of childhood hepatitis A immunization. Pediatr Infect Dis J 2003; 22: 904-914.

30. Valenzuela MT, Jacobs RJ, Arteaga O, Navarrete MS, Meyerhoff AS, Innis BL. Cost-effectiveness of universal childhood hepatitis A vaccination in Chile. Vaccine 2005; 23: 4110-4119.

31. Quezada A, Baron-Papillon F, Coudeville L, Maggi L. Universal vaccination of children against hepatitis A in Chile: a cost-effectiveness study. Rev Panam Salud Publica 2008; 23: 303-312. 